\title{
True Stress-True Strain Models for Structural Steel Elements
}

\author{
P. Arasaratnam, ${ }^{1}$ K. S. Sivakumaran, ${ }^{2}$ and M. J. Tait ${ }^{2}$ \\ ${ }^{1}$ AMEC Earth and Environmental, Edmonton, AB, Canada T6B 3P6 \\ ${ }^{2}$ Department of Civil Engineering, McMaster University, 1280 Main Street West, Hamilton, ON, Canada L8S 4L7
}

Correspondence should be addressed to K. S. Sivakumaran, siva@mcmaster.ca

Received 19 April 2011; Accepted 30 May 2011

Academic Editor: D. Li

Copyright () 2011 P. Arasaratnam et al. This is an open access article distributed under the Creative Commons Attribution License, which permits unrestricted use, distribution, and reproduction in any medium, provided the original work is properly cited.

\begin{abstract}
A standard uniaxial tensile test, which establishes the engineering stress-strain relationship, in general, provides the basic mechanical properties of steel required by a structural designer. Modern numerical analysis techniques used for analysis of large strain problems such as failure analysis of steel structures and elements metal forming, metal cutting, and so forth, will require implementation and use of true stress-true strain material characterization. This paper establishes a five stage true stress-strain model for A992 and 350W steel grades, which can capture the behavior of structural steel, including the postultimate behavior of steel, until fracture. The proposed model uses a power law in strain hardening range and a weighted power law in the postultimate range. The true stress-true strain model parameters were established through matching of numerical analysis results with the corresponding standard uniaxial tensile test experimental results. The material constitutive relationship so derived was then applied to predict the load-deformation behavior of coupons with a hole in the middle region subjected to direct tension loading. The predicted load-deformation behavior of perforated tension coupons agreed well with the corresponding test results validating the proposed characterization of the true stress-true strain relationship for structural steel.
\end{abstract}

\section{Introduction}

The finite-element- (FE-) method-based numerical analysis and other numerical analysis techniques are widely used in research involving structural steel and in the analysis and design of steel structures and elements. In research, numerical modeling techniques are often used to effectively expand the limited experimental results and used to investigate the influence of relevant parameters associated with a problem. Such simulations models for structural steel, however, require the use of realistic material stress-strain relationships, often extending up to fracture. Mechanical behavior of metallic type material, such as that of steel, is generally established by means of uniaxial tension test. Such tension test protocol [1], which was primarily created only for use in comparison of different steels, establishes the engineering stress and the engineering strain. Figure 1 shows a typical engineering stress-strain relationship for steel (solid line), where the stress was calculated as load divided by the original cross-section area of the tension coupon, and the engineering strain was calculated as change in length divided by the original gauge length. Such calculations, which do not recognize the area changes during increasing loads, are used for convenient of measurements of dimensions and will always show an elastic range (Region-I), strain hardening range (Region-IV), and a strain softening range (Region$\mathrm{V})$. The stress-strain relationship established on the basis of instantaneous deformed dimensions of the test coupon is known as the true stress-true strain relationship (dash line in Figure 1). For all practical purposes, the engineering relations and the true relations would coincide up to yield point; however, the two relations would diverge beyond this point. Figure 1 shows the qualitative differences between the engineering stress-strain relation and the true stressstrain relation. Accurate numerical modeling of large strain problems such as failure analysis of steel structures and elements, metal forming, metal cutting, and so forth, will require implementation and use of true stress-true strain material characterization. The objective of this investigation is to develop true stress-true strain relationships for structural steels in general, and for A992 and 350W steel grades in particular. This paper establishes five-stage true stress-true strain models for structural steels, based on numerical simulations calibrated against experimental 
uniaxial tension test results. Subsequently, the accuracy of these proposed models was established through comparisons with the experimental uniaxial tension test results associated with tension coupons having a small size central hole.

\section{Development of a True Stress-True Strain Model}

A standard uniaxial tensile test, in general, provides the basic mechanical properties of steel required by a structural designer; thus, the mill certificates provide properties such as yield strength $F_{y}$, ultimate strength $F_{u}$, and strain at fracture $\varepsilon_{f}$. The stress parameters are established using the original cross-section area of the specimen, and the average strain within the gauge length is established using the original gauge length. Because of the use of original dimensions in engineering stress-strain calculations, such relations will always show an elastic range, strain hardening range, and a strain softening range. As the load increases and when the specimen begins to fail, the cross-section area at the failure location reduces drastically, which is known as the "necking" of the section. In general, the strain softening is associated with the necking range of the test. Once the specimen begins to neck, the distribution of stresses and strains become complex and the magnitude of such quantities become difficult to establish [2]. Owing to the nonuniform stressstrain distributions existing at the neck for high levels of axial deformation, it has long been recognized that the changes in the geometric dimensions of the specimen need to be considered in order to properly describe the material response during the whole deformation process up to the fracture $[3,4]$. The true stress-true strain relationship is based on the instantaneous geometric dimensions of the test specimen. Figure 1 illustrates the engineering stress-strain relationship and the true stress-true strain relationships for structural steels. These relationships can be divided into five different regions as follows.

Region-I (Linear Elastic Range). During the initial stages of loading, stress varies linearly proportional to strain (up to a proportional limit). The proportional limit stress $F_{\mathrm{pl}}$ is typically established by means of $0.01 \%$ strain offset method [5]. Thus, the engineering stress can be related to engineering strain as follows: $F_{e}=E \varepsilon_{e}$ in the range $F_{e}<F_{\mathrm{pl}}$ and $\varepsilon_{e}<\varepsilon_{\mathrm{pl}}$, where $E$ is the initial elastic modulus of steel, which is often taken as 200,000 MPa. The corresponding true stress and the true strain, which recognize the deformed geometrics of the section during tests, can be established directly from the engineering stress and the engineering strain based on the concept of uniform stress, small dimensional change, and incompressible material, which is valid for steel. Resulting relations are $F_{t}=F_{e}\left(1+\varepsilon_{e}\right)$ and $\varepsilon_{t}=\ln \left(1+\varepsilon_{e}\right)$, where $F_{t}$ and $F_{e}$ are the true stress and engineering stress and $\varepsilon_{t}$ and $\varepsilon_{e}$ are the true strain and the engineering strain, respectively. The difference between true stress and engineering stress at proportional limit stress may be about $0.2 \%$; thus, the difference is insignificant in this region.

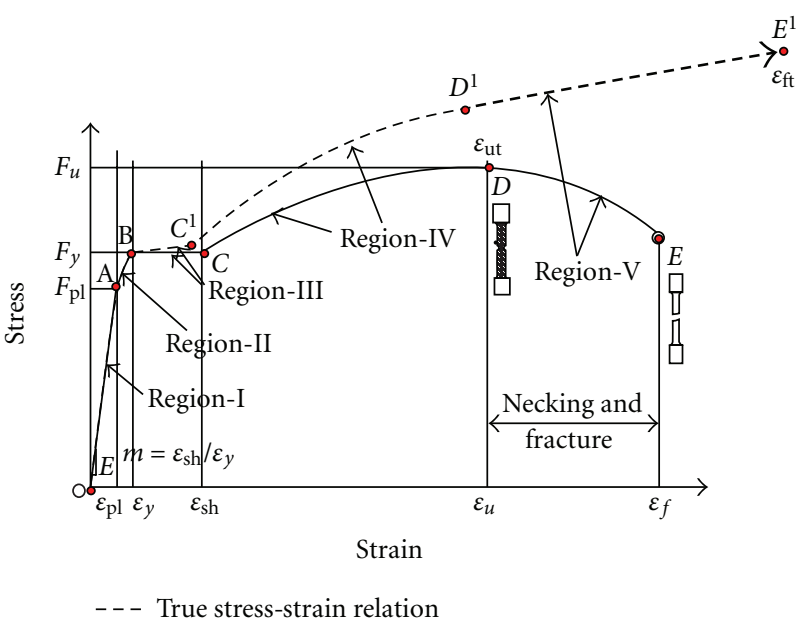

FIGURE 1: The engineering stress-strain relations and the proposed true stress-true strain material model.

Region-II (Nonlinear Elastic Range). This range represents a region between the proportional limit and the yield point. The yield point $F_{y}$ may be conveniently established as $0.2 \%$ strain offset method [5]. In this region, the variation of stress-strain relationship can be idealized as $F_{e}=F_{\mathrm{pl}}+E_{t}\left(\varepsilon_{e}-\right.$ $\varepsilon_{\mathrm{pl}}$ ), which is valid in the range $F_{\mathrm{pl}}<F_{e}<F_{y}$. Here, $E_{t}$ is the tangent modulus given as $E_{t}=\left(F_{y}-F_{\mathrm{pl}}\right) /\left(\varepsilon_{y}-\varepsilon_{\mathrm{pl}}\right)$. The true stress and true strain can be obtained as in the linear elastic range as follows: $F_{t}=F_{e}\left(1+\varepsilon_{e}\right)$ and $\varepsilon_{t}=\ln \left(1+\varepsilon_{e}\right)$, where $\varepsilon_{\mathrm{pl}}<\varepsilon_{e}<\varepsilon_{y}$.

Region-III (Yield Plateau). Some steels may exhibit yield plateau. The engineering stress in this region can be assumed as a constant value of $F_{y}$, which is valid in the range $\varepsilon_{y}<\varepsilon_{e}<$ $\varepsilon_{\mathrm{sh}}$, where $\varepsilon_{\mathrm{sh}}$ is the strain at the onset of strain hardening. The ratio between $\varepsilon_{\text {sh }}$ and $\varepsilon_{y}$ is defined here as $m=\varepsilon_{\text {sh }} / \varepsilon_{y}$. The value for $m$ must be determined from the uniaxial tension test. The true stress and true strain can be obtained as in the linear elastic range as; $F_{t}=F_{y}\left(1+\varepsilon_{e}\right)$ and $\varepsilon_{t}=\ln \left(1+\varepsilon_{e}\right)$, where $\varepsilon_{y}<\varepsilon_{e}<\varepsilon_{\text {sh }}$.

Region-IV (Strain Hardening). At the end of yield plateau, strain hardening begins with a subsequent increase in stress. Region-IV includes the strain hardening range up to ultimate strength when the test specimen may begin to exhibit necking. Though this region involves a nonlinear stressstrain relation, it is postulated that the true stress and the true strain can be obtained using the relations $F_{t}=F_{e}\left(1+\varepsilon_{e}\right)$ and $\varepsilon_{t}=\ln \left(1+\varepsilon_{e}\right)$. However, a power law is often used to relate the true stress to the true strain in this strain hardening region $[6,7]$. A power law of the form $F_{t}=F_{\mathrm{ut}} \cdot\left(\varepsilon_{t} / \varepsilon_{\mathrm{ut}}\right)^{n}$ is proposed herein, where $F_{\text {ut }}$ and $\varepsilon_{\text {ut }}$ are the true stress and true strain associated with the ultimate tensile strength $F_{u}$. The value for $n$ must be established for different steel grades which may be achieved using a least square analysis of the corresponding experimental results. This range is valid for $\varepsilon_{\mathrm{sh}}<\varepsilon_{e}<\varepsilon_{u}$. 
Region-V (Strain Softening). This region represents the behavior of the material in the apparent strain softening region. As explained earlier, the apparent strain softening is due to the use of the original cross-sectional area, and should the actual cross-sectional area be used, the stress and strain would continue to increase. The true stress-strain relations cannot be established in this region from engineering stress-strain values; thus, an experimental-numerical iterative approach was used in this study to derive the true stress-strain material characterization for this region. Zhano and $\mathrm{Li}[8]$ proposed that the parameters for a true stress-true strain relation be determined by using iterative FE method with an experimental tensile load-extension curve as a target. Although this method establishes the true stress-true strain relations from standard tensile test results without measurements of the deformed dimensions of the test specimens, the main shortcoming is that the entire stressstrain relation during necking is treated as an unknown and a trial and error procedure is used for a series of strain intervals until good correlation with the experimental results is attained. By nature, Zhano and Li [8] proposed method is computationally intensive and time consuming. Ling [9] proposed a weighted-average method for determining the uniaxial true stress versus true strain relation during necking. This method requires identification of a lower and an upper bound for the true stress-strain function during necking and expresses the true stress-strain relation as the weighted average of these two bounds. According to Ling's [9] method, a power-law fit, which represents strain hardening region of the flow curve, can be used as the lower bound whereas a linear strain hardening model can be used as the upper bound. Accordingly, the lower bound power law is $F_{t}=F_{\mathrm{ut}}$. $\left(\varepsilon_{t} / \varepsilon_{\mathrm{ut}}\right)^{n}$, which was established in Region-IV and the upper bound linear hardening model could be $F_{t}=\left(a_{0}+a_{1} \varepsilon_{t}\right)$, where constants are $a_{0}=F_{\mathrm{ut}} \cdot\left(1-\varepsilon_{\mathrm{ut}}\right)$ and $a_{1}=F_{\mathrm{ut}}$. Based on the weighted-average method, the true stress-strain relation in the postultimate strength region (Region- $\mathrm{V})$ may be derived as $F_{t}=F_{\mathrm{ut}}\left[w \cdot\left(\varepsilon_{t} / \varepsilon_{\mathrm{ut}}\right)^{n}+(1-w) \cdot\left(1+\varepsilon_{t}-\varepsilon_{\mathrm{ut}}\right)\right]$, where $w$ is the unknown weighting constant. The weighting constant $\mathrm{w}$ has to be established in an iterative manner by numerical simulation of a tensile test until a good correlation is achieved between the calculated and the experimental load extension curve.

In summary, this paper proposes a five stage characterization for the true stress-true strain relations for structural steel. The following parameters, namely, initial modulus of elasticity $E$, proportional limit stress $F_{\mathrm{pl}}$, tangent modulus $E_{t}$, yield point $F_{y}$, ratio between strain at strain hardening and strain at yielding $m$, true stress and true strain associated with the ultimate tensile strength $F_{u}$ designated herein as $F_{\mathrm{ut}}, \varepsilon_{\mathrm{ut}}$, respectively, power-law material constant $n$, and the weighting constant $w$ need to be obtained from representative uniaxial stress-strain relations for the steel grade. The next section describes an experimental program conducted to establish the above parameters for ASTM A992 steel and the $350 \mathrm{~W}$ steel grades and to validate the proposed model. The A992 is a relatively new steel grade for building construction in North America. The 350W steel is the Canadian standard CSA G40.21 steel [10], which is somewhat equivalent to ASTM A572 Grade 50 steel.

\section{True Stress-True Strain Model Parameters}

The true stress-true strain model parameters were established through amalgamation of experimental and numerical modeling techniques. The test program considered twenty eight tensile coupons, fourteen each from two different steel grades, namely, ASTM A992 steel and the $350 \mathrm{~W}$ steel. The tensile coupons for this investigation were cut along the rolling direction (length direction) of standard W310 $\times$ 39 (W12 $\times 26)$ wide flange beam sections. For each steel grade, eight coupons were taken from the flanges and six coupons were from the web of the section. The fabrication dimensions of the tensile coupons were in accordance with ASTM A370-10 [1] specifications and recommendations. For each specimen, three thickness measurements and three width measurements were taken at different locations within the reduced cross-section of the tensile coupons, and the average thickness and the average width of the test coupons were established. The thickness of the flange coupons was about $9.1 \mathrm{~mm}$ and thickness of the web coupons was $5.8 \mathrm{~mm}$. The width of the specimens was about $40 \mathrm{~mm}$. The initial gross cross-sectional area of each specimen was calculated based on these average dimensions. Some test specimens, which were used for the validation of the proposed model, had a central hole. The net area at the hole location was established based on measured hole diameter. The specimen ID (identification) used in this investigation is based on net area/gross area ratio of the test specimen. In the specimen ID related to the experimental investigation, A992/350W indicates the steel grade followed by $\mathrm{F} / \mathrm{W}$, which indicates the flange/web, followed by the value of net area/gross area ratio. For example, Specimen ID-A992-F-0.8 refers to a coupon cut from the flange of the A992 steel with net area/gross area ratio of 0.8 . Three identical flange and web coupons with no holes (shown as F1, W1, etc., in Figure 2 and Table 1) were used to establish the mechanical characteristics of the steel grades under consideration. Five remaining flange coupons and the three remaining web coupons were used as perforated tension coupons having different diameter holes at the centre of the specimens. Holes with net area/gross area ratios varying from 0.5 to 0.9 in increments of 0.1 were prepared for the flange coupons, whereas holes with net area/gross area ratios varying from 0.5 to 0.9 in increments of 0.2 were considered for the web coupons. The photographic image of the test specimens (solid sample with no holes, and perforated samples) is shown in Figures 2(a) and 2(b), respectively.

The coupons were tension tested in a Tinius Olsen machine with an axial load capacity of $600 \mathrm{kN}$. Each test specimen was first aligned vertically and centered with respect to the grips of the machine's loading platforms. Two extensometers having gauge lengths of $200 \mathrm{~mm}$ and $50 \mathrm{~mm}$ were attached on either face of the test coupon. The larger extensometer was used to establish the overall engineering stress-strain curve of the coupons, whereas 


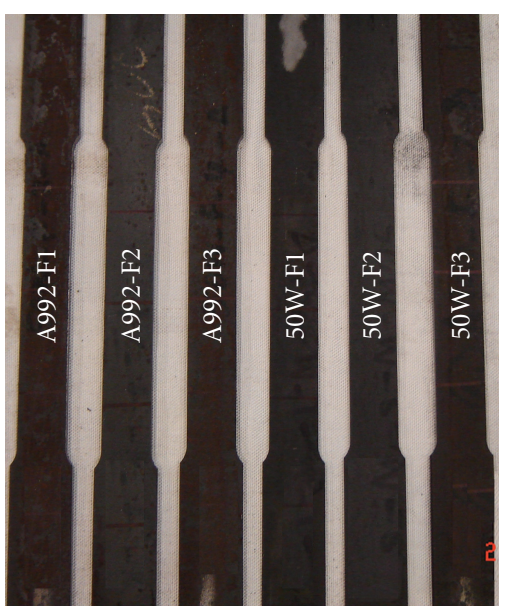

(a)

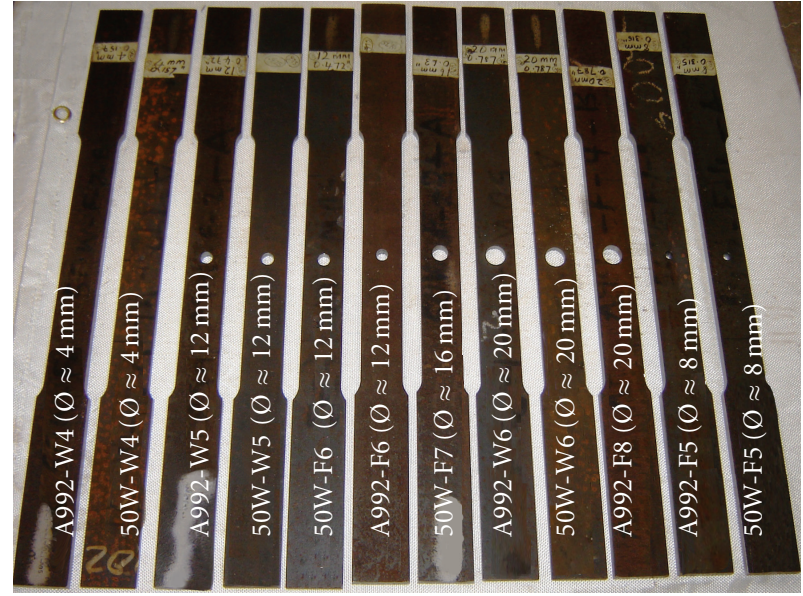

(b)

FIgURE 2: The tension coupons (a) with no holes and (b) with a central hole.

TABLE 1: Summary of mechanical properties of solid coupons (no hole).

\begin{tabular}{|c|c|c|c|c|c|c|c|c|c|c|c|c|}
\hline $\begin{array}{l}\text { Steel } \\
\text { grade }\end{array}$ & Specimen ID & $E(\mathrm{GPa})$ & $\begin{array}{c}F_{\mathrm{pl}} \\
(\mathrm{MPa})\end{array}$ & $\varepsilon_{\mathrm{pl}}$ & $\begin{array}{c}E_{t} \\
(\mathrm{GPa})\end{array}$ & $\begin{array}{c}F_{y} \\
(\mathrm{MPa})\end{array}$ & $\varepsilon_{y}$ & $\varepsilon_{\mathrm{sh}}$ & $m$ & $\begin{array}{c}F_{u} \\
(\mathrm{MPa})\end{array}$ & $\varepsilon_{u}$ & $\varepsilon_{f}$ \\
\hline (1) & (2) & (3) & (4) & (5) & (6) & $(7)$ & (8) & (9) & (10) & $(11)$ & (12) & (13) \\
\hline \multirow{8}{*}{$\begin{array}{l}\text { A992 } \\
\text { steel }\end{array}$} & A992-F1-1.0 & 204 & 422 & 0.0022 & 11.5 & 445 & 0.0042 & 0.0042 & 1.0 & 579 & 0.1348 & 0.2041 \\
\hline & A992-F2-1.0 & 203 & 418 & 0.0022 & 12.4 & 443 & 0.0042 & 0.0042 & 1.0 & 585 & 0.1353 & 0.2106 \\
\hline & A992-F3-1.0 & 201 & 390 & 0.0020 & 25.7 & 445 & 0.0042 & 0.0042 & 1.0 & 568 & 0.1441 & 0.2100 \\
\hline & (Flange $)_{\text {ave }}$ & 203 & 410 & 0.0021 & 16.5 & 444 & 0.0042 & 0.0042 & 1.0 & 577 & 0.1381 & 0.2082 \\
\hline & A992-W1-1.0 & 202 & 405 & 0.0020 & 00.0 & 405 & 0.0020 & 0.0156 & 7.8 & 568 & 0.1620 & 0.2083 \\
\hline & A992-W2-1.0 & 201 & 415 & 0.0021 & 00.0 & 415 & 0.0021 & 0.0132 & 6.3 & 591 & 0.1599 & 0.2023 \\
\hline & A992-W3-1.0 & 202 & 406 & 0.0020 & 00.0 & 406 & 0.0020 & 0.0154 & 7.7 & 561 & 0.1446 & 0.2308 \\
\hline & $(\mathrm{Web})_{\mathrm{ave}}$ & 202 & 409 & 0.0020 & 00.0 & 409 & 0.0020 & 0.0148 & 7.3 & 573 & 0.1555 & 0.2138 \\
\hline \multirow{8}{*}{$\begin{array}{l}350 \mathrm{~W} \\
\text { steel }\end{array}$} & 350W-F1-1.0 & 208 & 392 & 0.0020 & 17.2 & 427 & 0.0040 & 0.0040 & 1.0 & 581 & 0.1412 & 0.2282 \\
\hline & $350 \mathrm{~W}-\mathrm{F} 2-1.0$ & 215 & 403 & 0.0021 & 11.1 & 424 & 0.0040 & 0.0040 & 1.0 & 575 & 0.1443 & 0.2083 \\
\hline & 350W-F3-1.0 & 216 & 400 & 0.0020 & 15.6 & 430 & 0.0040 & 0.0040 & 1.0 & 578 & 0.1307 & 0.2240 \\
\hline & (Flange $)_{\text {ave }}$ & 213 & 398 & 0.0020 & 14.6 & 427 & 0.0040 & 0.0040 & 1.0 & 578 & 0.1387 & 0.2202 \\
\hline & $350 \mathrm{~W}-\mathrm{W} 1-1.0$ & 195 & 414 & 0.0021 & 00.0 & 414 & 0.0021 & 0.0160 & 7.6 & 571 & 0.1595 & 0.2054 \\
\hline & $350 \mathrm{~W}-\mathrm{W} 2-1.0$ & 195 & 413 & 0.0021 & 00.0 & 413 & 0.0021 & 0.0140 & 6.7 & 593 & 0.1292 & 0.1771 \\
\hline & $350 \mathrm{~W}-\mathrm{W} 3-1.0$ & 213 & 422 & 0.0020 & 00.0 & 422 & 0.0020 & 0.0158 & 7.9 & 581 & 0.1702 & 0.2025 \\
\hline & $(\text { Web })_{\text {ave }}$ & 201 & 416 & 0.0021 & 00.0 & 416 & 0.0021 & 0.0153 & 7.4 & 582 & 0.1530 & 0.1950 \\
\hline
\end{tabular}

the smaller extensometer, which had a greater sensitivity, allowed a more accurate estimation of the initial modulus $(E)$ and the proportional limit stress $\left(F_{\mathrm{pl}}\right)$. Figure 3 shows the engineering stress-engineering strain relationships obtained during these tests. As evident from this figure, consistent results were obtained for three identical specimens. Furthermore, the specimens from the web exhibited yield plateau, whereas no such behavior was observed in the specimens taken from the flange. Table 1 summarizes the mechanical properties established from the solid coupon tensile tests. The average yield strength $F_{y}$ and ultimate strength $F_{u}$ of the A992-flange coupons were calculated to be $444 \mathrm{MPa}$ and $577 \mathrm{MPa}$, respectively, resulting in the $F_{y} / F_{u}$ ratio of 0.77 . The average strains corresponding to the ultimate strength $\varepsilon_{u}$ and at fracture $\varepsilon_{f}$ were measured to be $13.8 \%$ and $20.8 \%$, respectively. Note that the above strains were based on $200 \mathrm{~mm}$ gauge length. The average $F_{y}$ and $F_{u}$ values for the A992-web coupons were $409 \mathrm{MPa}$ and $573 \mathrm{MPa}$, respectively, resulting in the $F_{y} / F_{u}$ ratio of 0.71 . These coupons reached the ultimate strength at the strain of $15.6 \%$ and fractured at the strain of $21.4 \%$. The $350 \mathrm{~W}$ flange coupons had the $F_{y}$ and $F_{u}$ values of $427 \mathrm{MPa}$ and $578 \mathrm{MPa}$, respectively, resulting in the $F_{y} / F_{u}$ ratio of 0.74 . The average $\varepsilon_{u}$ and $\varepsilon_{f}$ values associated with these coupons were $13.9 \%$ and $22.0 \%$, respectively. The average $F_{y}$ and $F_{u}$ values of $350 \mathrm{~W}$-web coupons were measured to be $416 \mathrm{MPa}$ and $582 \mathrm{MPa}$, respectively, resulting in the $F_{y} / F_{u}$ ratio of 0.71 . These coupons had average $\varepsilon_{u}$ and $\varepsilon_{f}$ of $15.3 \%$ and 


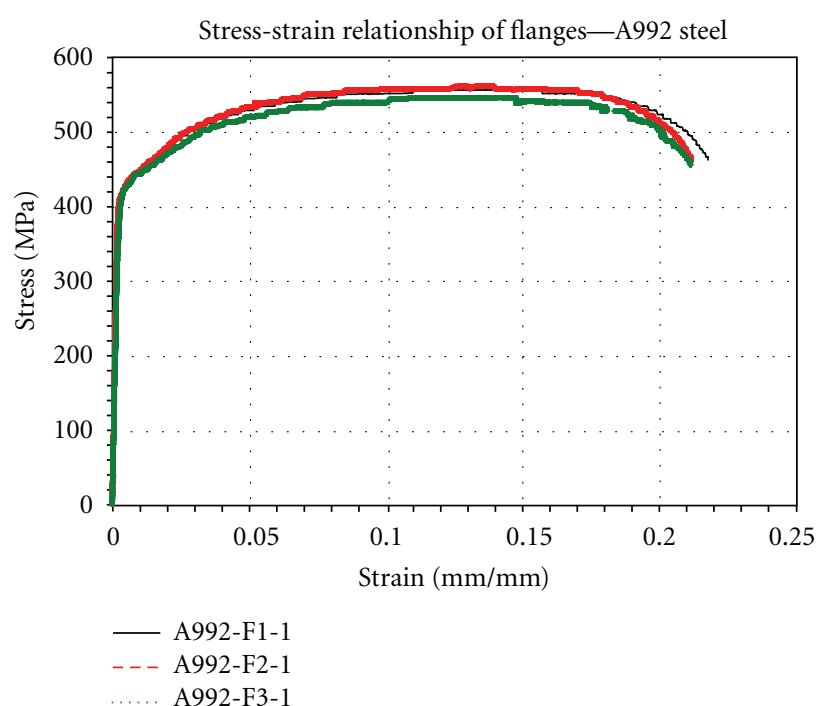

(a)

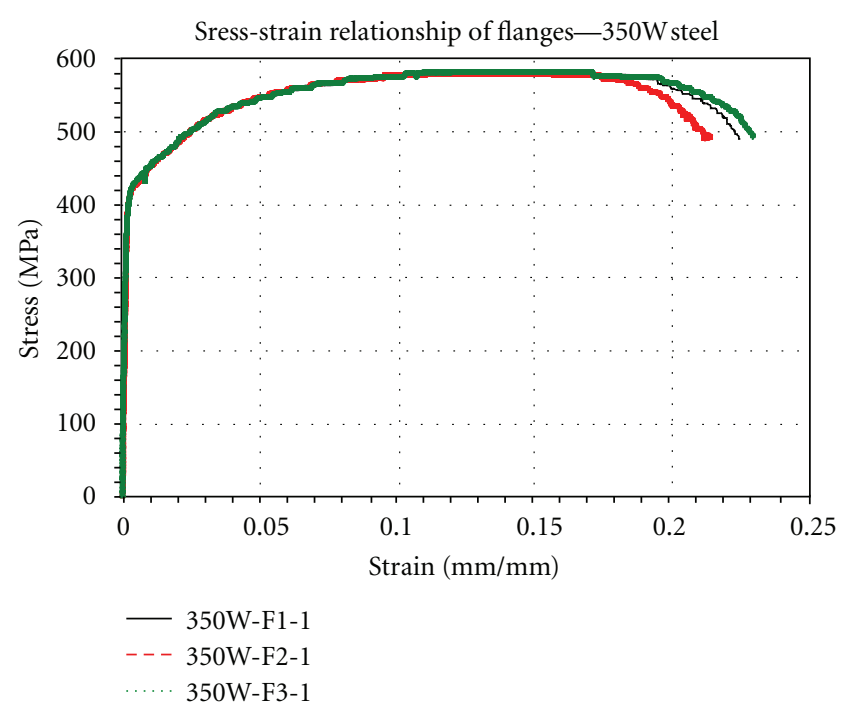

(c)

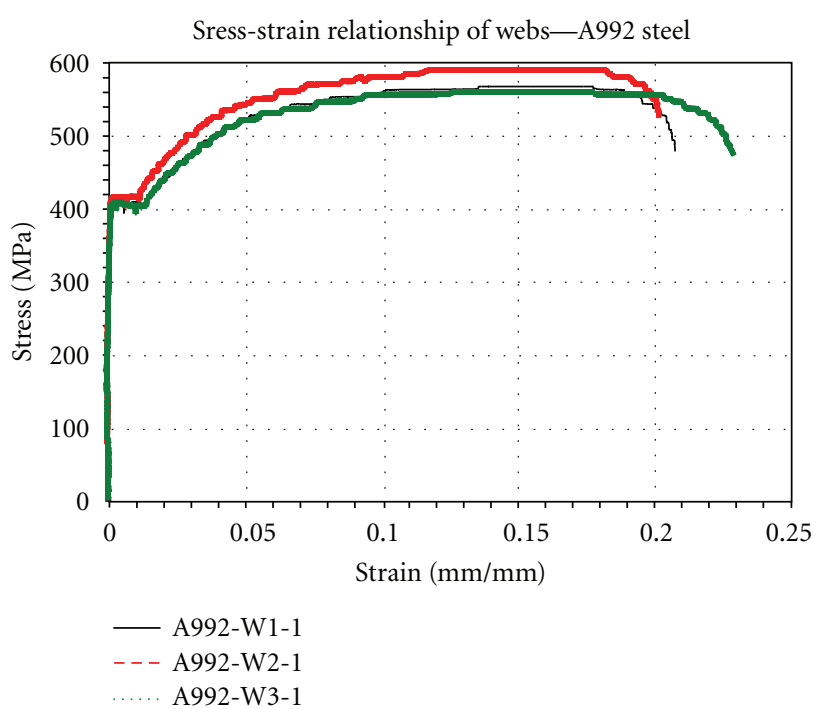

(b)

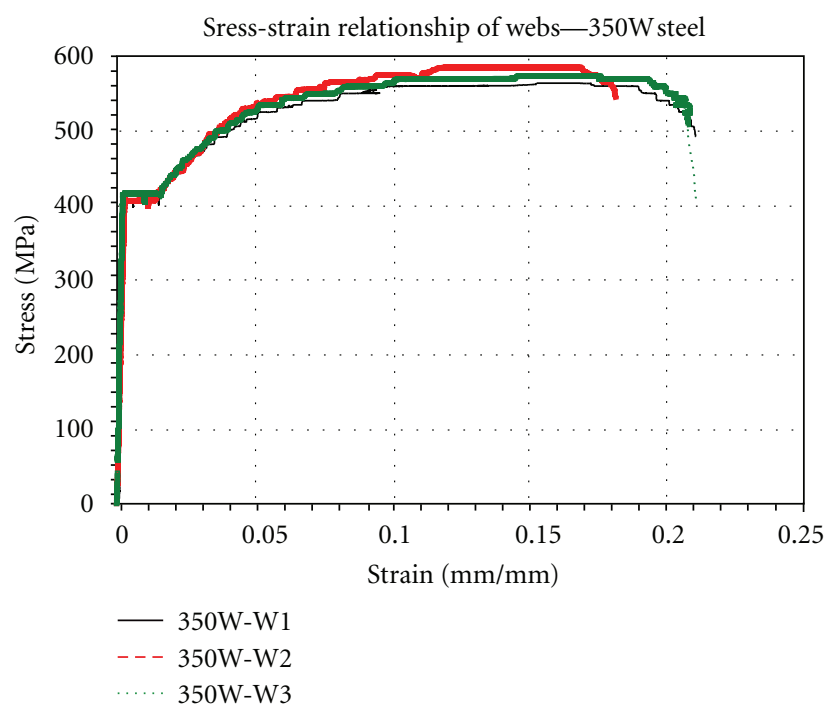

(d)

FIGURE 3: Experimental engineering stress-engineering strain relationships (over $200 \mathrm{~mm}$ gauge length).

$19.5 \%$, respectively. The $F_{y} / F_{u}$ ratio value for the A992-flange coupon was $4 \%$ higher than that of the $350 \mathrm{~W}$-flange coupon. The true stress-true strain model parameters for Regions-I, II, and III were extracted from these results and are shown in Table 2.

The Region-IV requires the power law parameter $n$, which was established through linear regression of the test results corresponding to that region. The test results considered for this region is between points $C$ and $D$ in Figure 1 and is valid for true stress-true strain region between points $C^{1}$ and $D^{1}$ shown in Figure 1. Figure 4 shows a representative calculation corresponding to $350 \mathrm{~W}$ web element. The experimental engineering stress and strains were first converted to true stress and strains, and then the strain hardening portion of the relationship was used to obtain a power law fit, which resulted in $n=0.1628$ for $350 \mathrm{~W}$ web element. Complete power law relationships for A992, 350W flange and web elements are given in Table 2.

The Region- $\mathrm{V}$ requires establishment of a weighting constant $w$, which is found here by trial and error. The task is to match the finite element numerical analysis results with the corresponding experimental results in this region. Here, the tensile test coupon was modeled using the finite element analysis package ADINA [11]. The model used the 4-node shell elements with six degrees of freedom per node. This element can be employed to model thick and thin general shell structures, and it accounts for finite strains by allowing for changes in the element thickness [12]. Also, this shell element can be efficiently used with plastic multilinear material models for large-displacement/large-strain analyses [3]. Each shell element employed $2 \times 2$ integration points in the mid surface (in $r$-s plane) and 3 Gauss numerical 
TABLE 2: True stress-true strain model parameters for A992 and 350W steel grades.

\begin{tabular}{|c|c|c|c|c|c|}
\hline & Region-I & Region-II & Region-III & Region-IV & Region-V \\
\hline \multirow[t]{3}{*}{$\begin{array}{l}\text { Steel grade- } \\
\text { element }\end{array}$} & $\begin{array}{c}\text { Linear elastic } \\
\text { range }\end{array}$ & $\begin{array}{c}\text { Nonlinear elastic } \\
\text { range }\end{array}$ & $\begin{array}{l}\text { Yield plateau } \\
\text { range }\end{array}$ & $\begin{array}{c}\text { Strain hardening } \\
\text { range }\end{array}$ & $\begin{array}{l}\text { Postultimate } \\
\text { strength range }\end{array}$ \\
\hline & $\varepsilon_{e}<\varepsilon_{\mathrm{pl}}$ & $\varepsilon_{\mathrm{pl}}<\varepsilon_{e}<\varepsilon_{y}$ & $\varepsilon_{y}<\varepsilon_{e}<\varepsilon_{\mathrm{sh}}$ & $\varepsilon_{\mathrm{sh}}<\varepsilon_{e}<\varepsilon_{u}$ & $\varepsilon_{u}<\varepsilon_{e}<\varepsilon_{f}$ \\
\hline & $\begin{array}{c}F_{e}=E \varepsilon_{e} \\
F_{t}=F_{e}\left(1+\varepsilon_{e}\right) \\
\varepsilon_{t}=\ln \left(1+\varepsilon_{e}\right)\end{array}$ & $\begin{aligned} F_{e}= & \left(E-E_{t}\right) \varepsilon_{\mathrm{pl}} \\
& +E_{t} \varepsilon_{e} \\
F_{t}= & F_{e}\left(1+\varepsilon_{e}\right) \\
\varepsilon_{t}= & \ln \left(1+\varepsilon_{e}\right)\end{aligned}$ & $\begin{aligned} F_{t} & =F_{y}\left(1+\varepsilon_{e}\right) \\
\varepsilon_{t} & =\ln \left(1+\varepsilon_{e}\right)\end{aligned}$ & $F_{t}=F_{\mathrm{ut}} \cdot\left(\varepsilon_{t} / \varepsilon_{\mathrm{ut}}\right)^{n}$ & $\begin{array}{c}F_{t}=F_{\mathrm{ut}}[w . \\
\left(\varepsilon_{t} / \varepsilon_{\mathrm{ut}}\right)^{n}+(1- \\
\left.w) \cdot\left(1+\varepsilon_{t}-\varepsilon_{\mathrm{ut}}\right)\right]\end{array}$ \\
\hline A992-flange & $\begin{array}{c}E=203 \mathrm{GPa} \\
F_{\mathrm{pl}}=410 \mathrm{MPa} \\
\varepsilon_{\mathrm{pl}}=0.0021\end{array}$ & $\begin{array}{c}E_{t}=16.5 \mathrm{GPa} \\
F_{y}=444 \mathrm{MPa} \\
\varepsilon_{y}=0.0042\end{array}$ & $\begin{array}{c}m=1.0 \\
\varepsilon_{y}=0.0042 \\
\varepsilon_{\mathrm{st}}=0.0042\end{array}$ & $\begin{array}{c}F_{t}=860.4\left(\varepsilon_{t}\right)^{0.1411} \\
F_{\mathrm{ut}}=653 \mathrm{MPa} \\
\varepsilon_{\mathrm{ut}}=0.1411\end{array}$ & $\begin{array}{c}w=0.6 \\
n=0.1411\end{array}$ \\
\hline A992-web & $\begin{array}{c}E=202 \mathrm{GPa} \\
F_{\mathrm{pl}}=409 \mathrm{MPa} \\
\varepsilon_{\mathrm{pl}}=0.0020\end{array}$ & $\begin{array}{c}E_{t}=00.0 \mathrm{GPa} \\
F_{y}=409 \mathrm{MPa} \\
\varepsilon_{y}=0.0020\end{array}$ & $\begin{array}{c}m=7.4 \\
\varepsilon_{y}=0.0020 \\
\varepsilon_{\text {st }}=0.0148\end{array}$ & $\begin{array}{c}F_{t}=942.8\left(\varepsilon_{t}\right)^{0.1611} \\
F_{\mathrm{ut}}=703 \mathrm{MPa} \\
\varepsilon_{\mathrm{ut}}=0.1611\end{array}$ & $\begin{array}{c}w=0.5 \\
n=0.1611\end{array}$ \\
\hline 350W-flange & $\begin{array}{c}E=213 \mathrm{GPa} \\
F_{\mathrm{pl}}=398 \mathrm{MPa} \\
\varepsilon_{\mathrm{pl}}=0.0020\end{array}$ & $\begin{array}{c}E_{t}=14.6 \mathrm{GPa} \\
F_{y}=427 \mathrm{MPa} \\
\varepsilon_{y}=0.0040\end{array}$ & $\begin{array}{c}m=1.0 \\
\varepsilon_{y}=0.0040 \\
\varepsilon_{\text {st }}=0.0040\end{array}$ & $\begin{array}{c}F_{t}=905.6\left(\varepsilon_{t}\right)^{0.1511} \\
F_{\mathrm{ut}}=681 \mathrm{MPa} \\
\varepsilon_{\mathrm{ut}}=0.1511\end{array}$ & $\begin{array}{c}w=0.6 \\
n=0.1511\end{array}$ \\
\hline $350 \mathrm{~W}$-web & $\begin{array}{c}E=201 \mathrm{GPa} \\
F_{\mathrm{pl}}=416 \mathrm{MPa} \\
\varepsilon_{\mathrm{pl}}=0.0021\end{array}$ & $\begin{array}{c}E_{t}=00.0 \mathrm{GPa} \\
F_{y}=416 \mathrm{MPa} \\
\varepsilon_{y}=0.0021\end{array}$ & $\begin{array}{c}m=7.3 \\
\varepsilon_{y}=0.0021 \\
\varepsilon_{\text {st }}=0.0153\end{array}$ & $\begin{array}{c}F_{t}=943.2\left(\varepsilon_{t}\right)^{0.1628} \\
F_{\mathrm{ut}}=702 \mathrm{MPa} \\
\varepsilon_{\mathrm{ut}}=0.1628\end{array}$ & $\begin{array}{c}w=0.5 \\
n=0.1628\end{array}$ \\
\hline
\end{tabular}

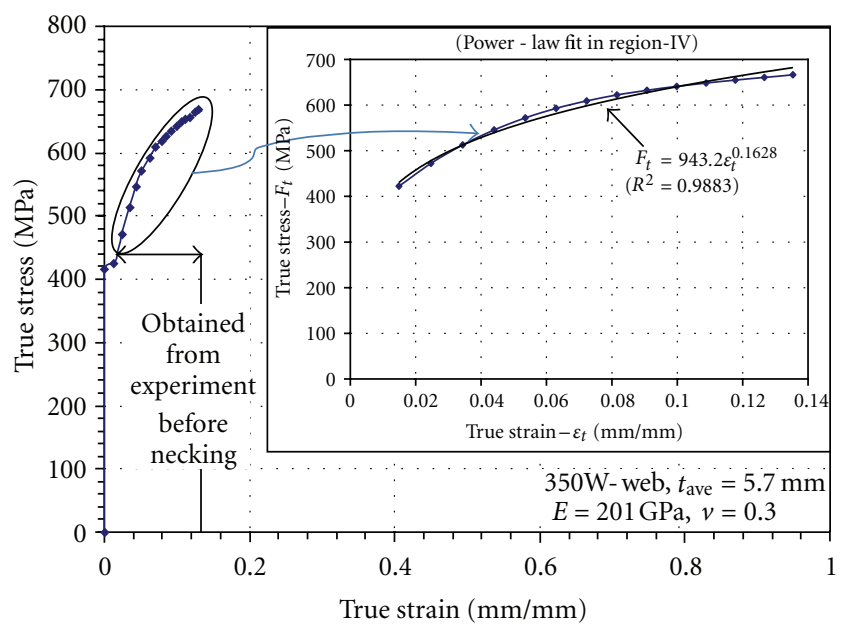

FIGURE 4: True stress-true strain relationships in region IV-350Wweb.

integration points through thickness (in $t$-direction). The model also incorporated a geometric imperfection (maximum amplitude of $0.1 \%$ of the width $-40 \mathrm{~mm}$ ) of a half sine wave along the gauge length in order to cause diffuse necking. The analysis incorporated both geometric and material nonlinearities (von Mises yield criterion and isotropic strain hardening rule). One edge of the model was fully restrained while the other end was subjected to a uniform displacement. For analysis of members with mid-hole, which is presented in the next section, a finer mesh was used for a $50 \mathrm{~mm}$ length of the middle region, where the strain gradient is expected to be large. The true stress and strain relationship for RegionsI, II, III, and IV used in the analysis model was derived from the engineering stress-strain curve obtained from tension coupon tests as described above and as given in Table 2. The material model in Region- $\mathrm{V}$ first requires a true fracture strain $\varepsilon_{\mathrm{ft}}$ (point $E^{1}$ shown in Figure 1). Study by Khoo [13] indicated that the localized fracture strains for structural steel under uniaxial tensile load could vary between $80 \%$ and $120 \%$. Therefore, this study considered a true fracture strain of $100 \%$ (i.e., $\varepsilon_{\mathrm{ft}}=100 \%$.) corresponding to point $E^{1}$.

Figure 5 shows a representative FE model used to reproduce the standard coupon test and the associated failure of the model due to necking followed by fracture. This figure also shows the boundary conditions used in the FE model. The weighting constant $w$ for Region- $\mathrm{V}$ has to be established in an iterative manner by numerical simulation of tensile tests until a good correlation is achieved between the calculated and the experimental load extension curves. In order to illustrate the influence of the weighting constant, three different values for $w=1.0,0.6$, and 0.4 were considered in the numerical simulations. Figure 6 shows the resulting FE predicted responses along with the experimental responses of three identical tension coupons (A992 flange). The weighting factor $w=1.0$, which represents the Region- $\mathrm{V}$ by a power-law hardening model, results in a numerical response well below the experimental curves. However, for $w=0.4$, the numerical curve was slightly above the experimental curve and sustains larger fracture strain. The weighting value $w=0.6$ gives the best fit for this set of experimental results. Although a suitable weight constant $w$ to reproduce the experimental stress-strain curve needs to be established by trial and error approach, only a few trials were required in this study. Table 2 shows the values of the weighting constants for A992, 350W flange and web elements. Table 3 summarizes the experimental and FE predicted values for the engineering stresses and strains at fracture. The predicted stresses and strains were in good agreement with the corresponding experimental values considering the three identical specimens. The stresses 


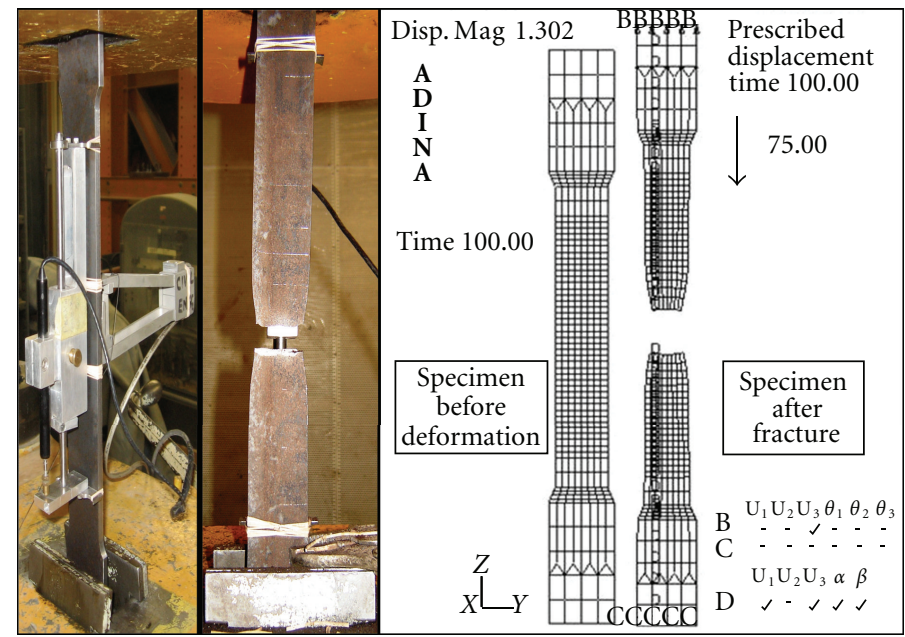

FIGURE 5: Comparison of failure pattern of test sample with FE simulation results.

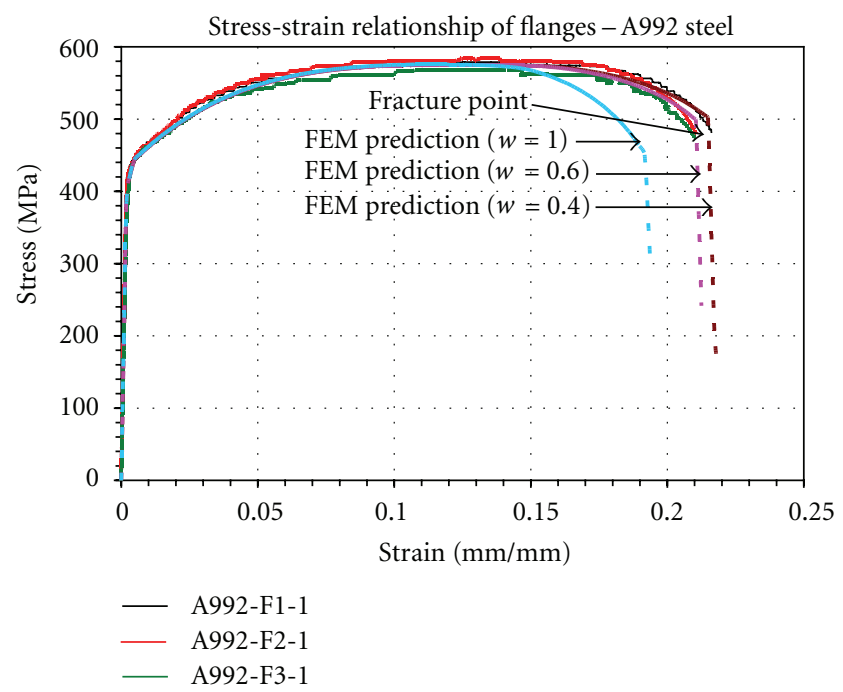

FIGURE 6: Influence of weighting constant.

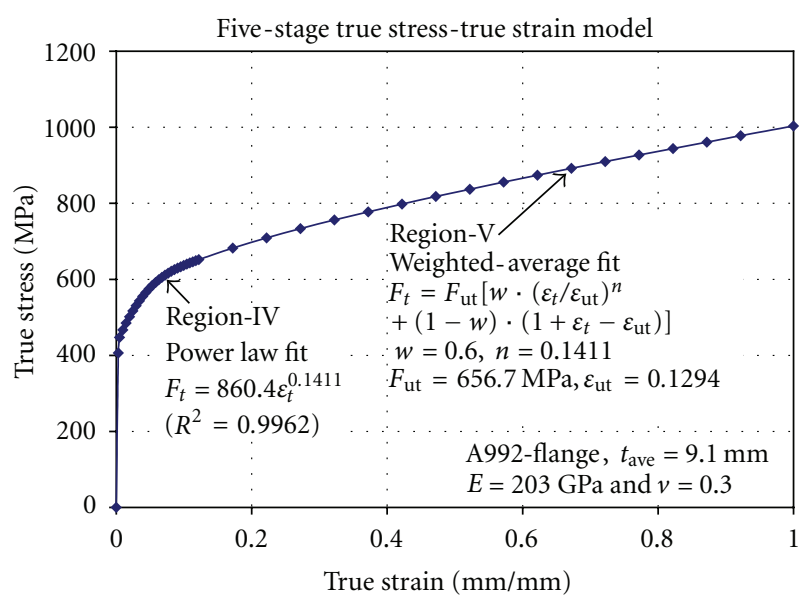

Figure 7: Proposed true stress-true strain model for A992-flange steel. at fracture varied as high as a maximum $3 \%$, whereas the fracture strain differed by a maximum $5 \%$ when compared to the corresponding experimental values. Figure 7 shows the resulting true stress-true strain model for A992 flange element.

\section{Verification of the Proposed True Stress-True Strain Model}

The proposed true stress-true strain constitutive relations were further validated by incorporating them in a finite element model for tension coupons having a central hole and through comparison of the FE numerical results with the corresponding experimental results. This part of the investigation considered sixteen test cases consisting of eight A992 steel grade and eight 350W steel grade. Each steel grade considered five flange specimens and three web specimens containing a central hole. Holes with net area/gross area ratios varying from 0.5 to 0.9 in increments of 0.1 were prepared for the flange coupons, whereas holes with net area/gross area ratios varying from 0.5 to 0.9 in increments of 0.2 were considered for the web coupons. Figure 2 shows these test specimens. Figure 8 shows a representative test specimen with a hole and the corresponding FE model. This figure also shows the experimental failure mode and the fracture during FE analysis. Overall, visually similar failure patterns were observed. Figure 9 establishes the comparison between the FE results and the corresponding test results for the perforated specimens obtained from the flanges and webs of the A992 steel section. As can be seen in this figure, the stress-strain responses obtained through FE model incorporating the proposed true stress-true strain constitutive relations showed a reasonably good agreement with the test responses of similar samples. Similar comparisons were also made on the $350 \mathrm{~W}$ steel perforated tension members. Again, the numerical simulations agreed well with the experimental results, particularly in predicting the ultimate strengths of perforated samples. Table 4 presents the experimentally 


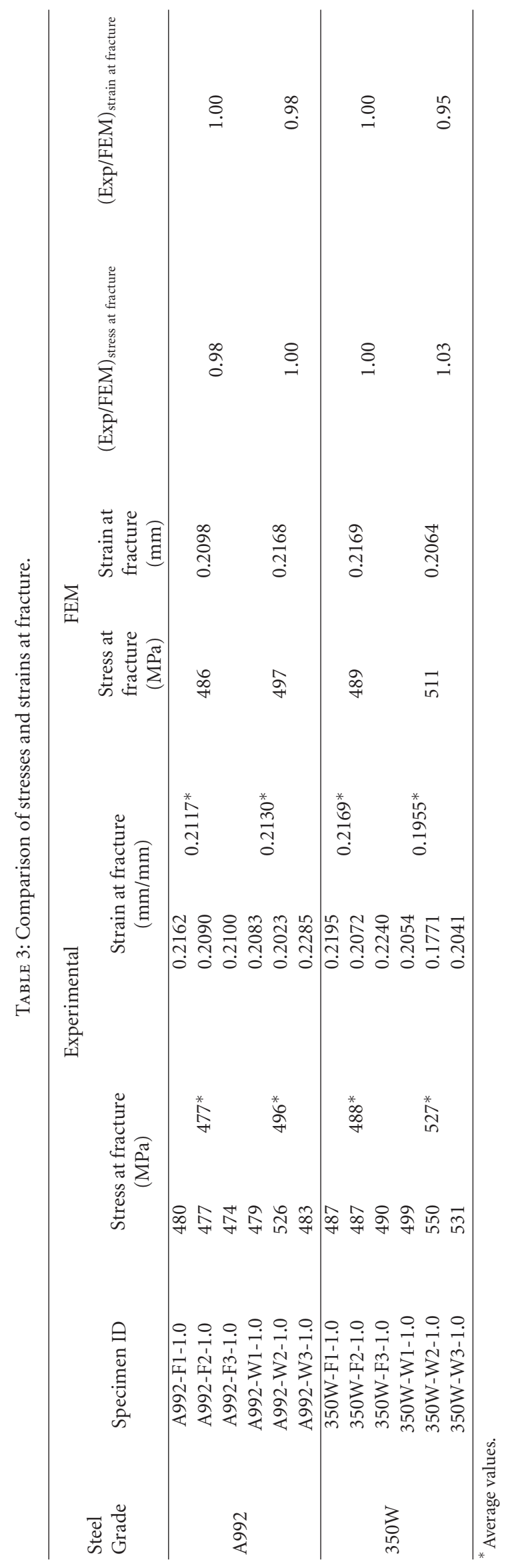




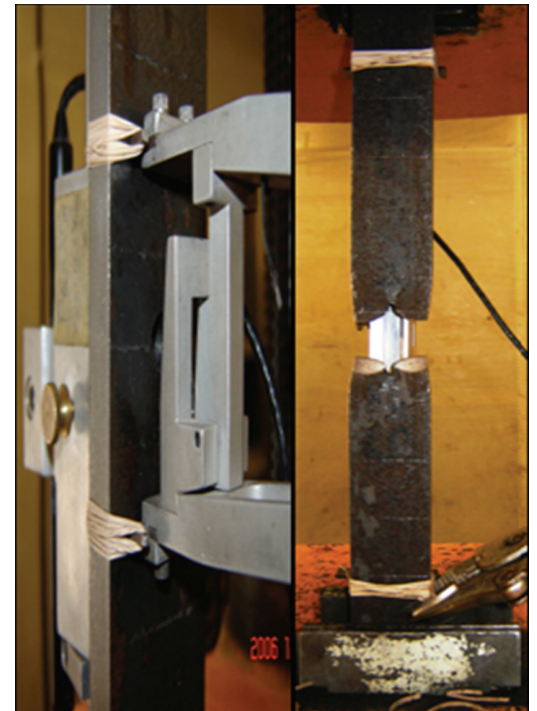

(a)

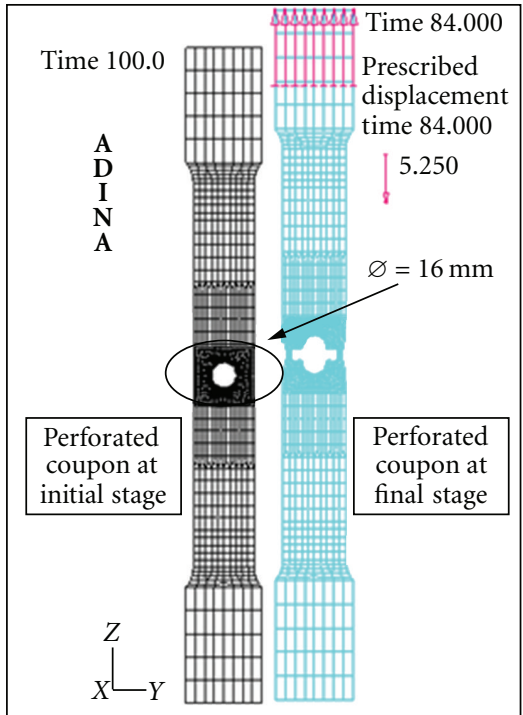

(b)

FIGURE 8: Comparison of failure pattern observed in the experiment and FE simulation-perforated sample.

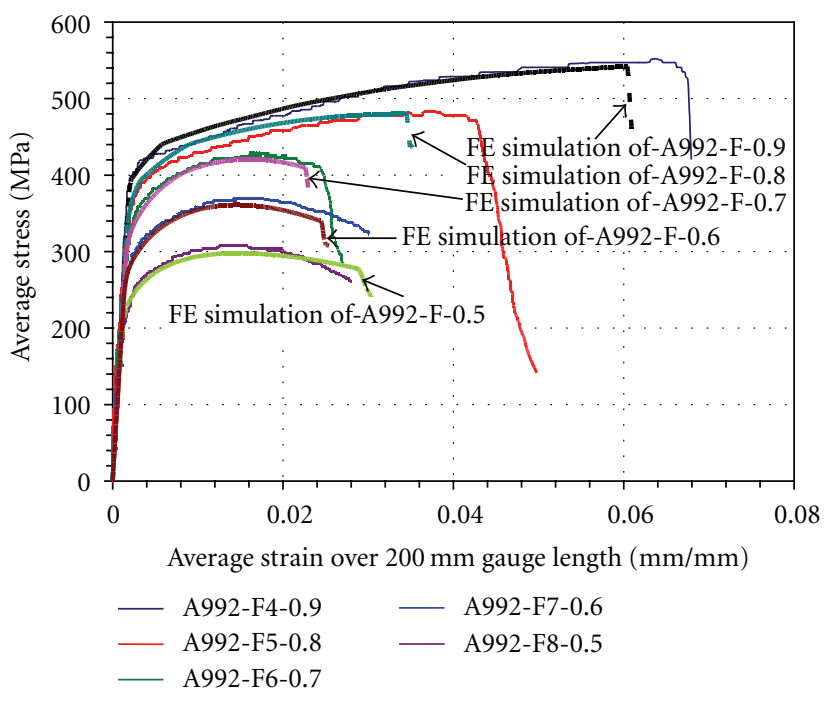

(a)

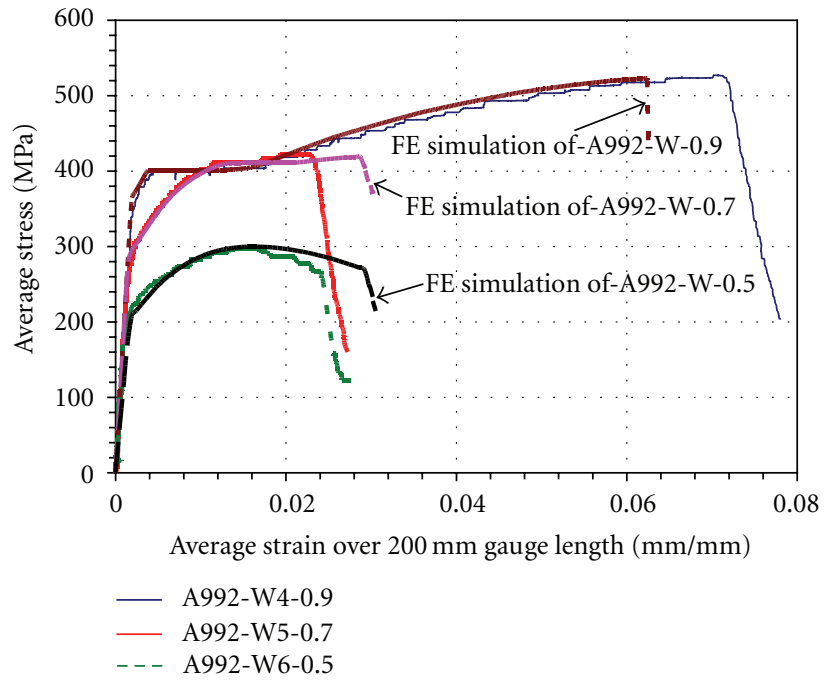

(b)

FigURE 9: Analyses of perforated tension coupons-A992 steel grade.

and numerically obtained ultimate strength values for the perforated coupons. As seen in the fifth column of Table 4, the FE results varied by less than $5 \%$ when compared to the experimental results indicating the validity of the proposed true stress-true strain material characterization model.

\section{Conclusions}

Steel structures construction often necessitates fabrication of holes in the flanges of steel beams [14]. If one has to build finite element models for such studies or other similar studies on steel structures and elements, then such FE models require realistic material stress-strain relationships, which can capture the fracture of steel as well. Traditional uniaxial tension tests provide engineering stress-engineering strain results which are not accurate particularly in the strain hardening range and in the postultimate strength range. This investigation developed true stress-true strain relationships for structural steels in general, and for A992 and 350W steel grades in particular. This paper established five-stage true stress-true strain constitutive models for structural steels, based on numerical simulations calibrated against experimental uniaxial tension test results. The proposed model uses a power law in strain hardening range and a weighted powerlaw in the postultimate range. The true stress-true strain 
TABLE 4: Comparison of experimental test results with FE prediction for perforated samples.

\begin{tabular}{|c|c|c|c|c|}
\hline Steel grade & Specimen ID & $\begin{array}{l}\text { Experimental ultimate } \\
\text { stress } F_{u}^{\text {Exp }}=\left(P_{u} / A_{g}\right)_{\text {Exp }} \\
(\mathrm{MPa})\end{array}$ & $\begin{array}{c}\text { FEM ultimate stress } \\
F_{u}{ }^{\mathrm{FEM}}=\left(P_{u} / A_{g}\right)_{\mathrm{FEM}} \\
(\mathrm{MPa})\end{array}$ & $F_{u}{ }^{\operatorname{Exp}} / F_{u}{ }^{\text {EEM }}$ \\
\hline (1) & (2) & (3) & $(4)$ & (5) \\
\hline \multirow{8}{*}{ A992 } & A992-F-0.9 & 547 & 542 & 1.01 \\
\hline & A992-F-0.8 & 482 & 480 & 1.00 \\
\hline & A992-F-0.7 & 429 & 423 & 1.01 \\
\hline & A992-F-0.6 & 369 & 362 & 1.02 \\
\hline & A992-F-0.5 & 308 & 298 & 1.03 \\
\hline & A992-W-0.9 & 528 & 523 & 1.01 \\
\hline & A992-W-0.7 & 422 & 418 & 1.01 \\
\hline & A992-W-0.5 & 297 & 299 & 0.99 \\
\hline \multirow{8}{*}{$350 W$} & 350W-F-0.9 & 548 & 547 & 1.00 \\
\hline & $350 \mathrm{~W}-\mathrm{F}-0.8$ & 489 & 488 & 1.00 \\
\hline & $350 \mathrm{~W}-\mathrm{F}-0.7$ & 427 & 427 & 1.00 \\
\hline & $350 \mathrm{~W}-\mathrm{F}-0.6$ & 366 & 366 & 1.00 \\
\hline & $350 \mathrm{~W}-\mathrm{F}-0.5$ & 311 & 312 & 1.00 \\
\hline & $350 W-W-0.9$ & 540 & 543 & 0.99 \\
\hline & $350 W-W-0.7$ & 417 & 417 & 1.00 \\
\hline & $350 \mathrm{~W}-\mathrm{W}-0.5$ & 291 & 302 & 0.96 \\
\hline
\end{tabular}

model parameters were established through a combination of experimental and numerical modeling techniques. The stresses and strains at fracture for the standard coupons based on numerical analysis differed by less than $5 \%$ when compared to the corresponding results from the experiment. The proposed material constitutive relation was further verified through comparison of finite element analysis loaddeformation behavior with the corresponding experimental results for perforated tension coupons.

\section{Notations}

$\begin{array}{ll}E, E_{t}: & \text { Elastic modulus, tangent modulus } \\ F_{e}, F_{\mathrm{pl}}, F_{y}, F_{u}: & \begin{array}{l}\text { Engineering stress, engineering stress } \\ \text { at proportional limit, engineering }\end{array} \\ & \text { stress at yielding, engineering stress at } \\ & \text { ultimate strength of solid sample } \\ & \text { True stress, true stress corresponding } \\ & \text { to ultimate strength } \\ & \text { Ratio between strain at strain } \\ m: & \text { hardening and strain at yielding } \\ & \text { Power-law material constant } \\ n: & \text { Weight constant } \\ w: & \text { Engineering strain, engineering yield } \\ \varepsilon_{e}, \varepsilon_{y}, \varepsilon_{\mathrm{pl}}, \varepsilon_{\mathrm{sh}}, \varepsilon_{u}, \varepsilon_{f}: & \text { strain, engineering strain at } \\ & \text { proportional limit, engineering strain } \\ & \text { at onset of strain hardening, ultimate } \\ & \text { engineering strain, engineering } \\ & \text { fracture strain } \\ & \text { True strain, true stain corresponding } \\ & \text { to ultimate strength, true fracture } \\ & \text { strain. }\end{array}$

\section{References}

[1] ASTM, "Standard Test Methods and Definitions for Mechanical Testing of Steel Products-ASTM Standards A370-10," American Society for Testing and Materials, USA, 2010.

[2] A. C. Mackenzie, J. W. Hancock, and D. K. Brown, "On the influence of state of stress on ductile failure initiation in high strength steels," Engineering Fracture Mechanics, vol. 9, no. 1, pp. 167-188, 1977.

[3] E. E. Cabezas and D. J. Celentano, "Experimental and numerical analysis of the tensile test using sheet specimens," Finite Elements in Analysis and Design, vol. 40, no. 5-6, pp. 555-575, 2004.

[4] K. T. Jaquess and K. Frank, "Characterization of the Material Properties of Rolled Sections," Tech. Rep. SAC/BD-99/07, SAC Joint Venture, USA, 1999.

[5] T. V. Galambos, Guide to Stability Design Criteria for Metal Structures, John Wiley \& Sons, New York, NY, USA, 5th edition, 1998.

[6] J. H. Hollomon, “Tensile deformation," Transaction of American Institute of Mechanical Engineering, vol. 162, pp. 268-277, 1945.

[7] M. Bruneau, C. M. Uang, and A. Whittaker, Ductile Design of Steel Structures, McGraw-Hill, New York, NY, USA, 1998.

[8] K. S. Zhano and Z. H. Li, "Numerical analysis of the stressstrain curve and fracture initiation for ductile material," Engineering Fracture Mechanics, vol. 49, no. 2, pp. 235-241, 1994.

[9] Y. Ling, "Uniaxial true stress-strain after necking," $A M P$ Journal of Technology, vol. 5, pp. 37-48, 1996.

[10] CISC, Handbook of Steel Construction, Canadian Institute of Steel Construction, Markham, Ontario, Canada, 10th edition, 2010.

[11] ADINA, ADINA 8.3 Version User Manual, ADINA R\&D, Inc., Watertown, Mass, USA, 2006. 
[12] K. J. Bathe, Finite Element Procedures, Prentice Hall, Englewood Cliffs, NJ, USA, 1996.

[13] A. H. Khoo, Ductile fracture of steel, Ph.D. thesis, University of Alberta, Alberta, Canada, 2000.

[14] CSA, S16-09 Design of Steel Structures, Canadian Standards Association, Mississauga, Ontario, Canada, 2009. 

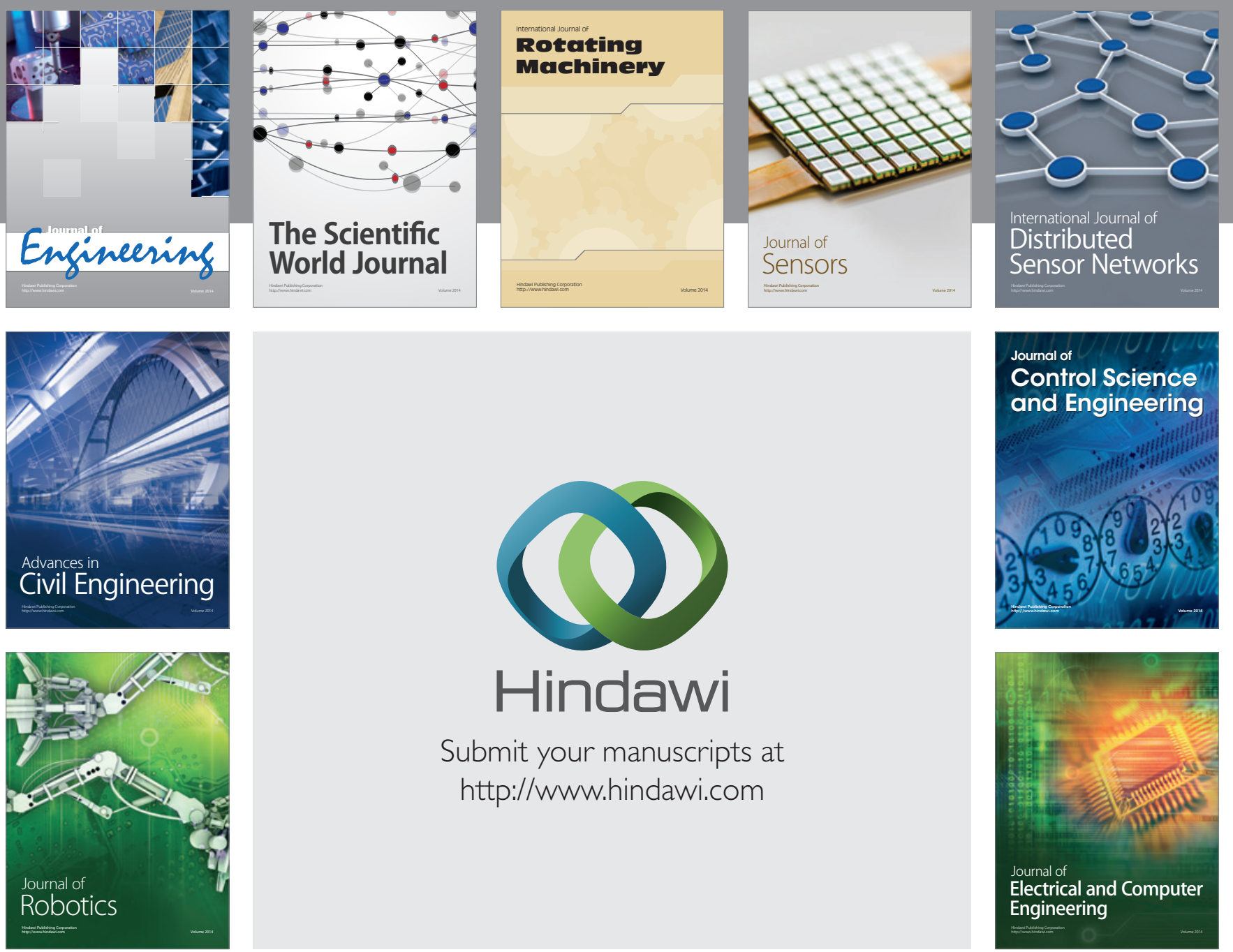

Submit your manuscripts at

http://www.hindawi.com
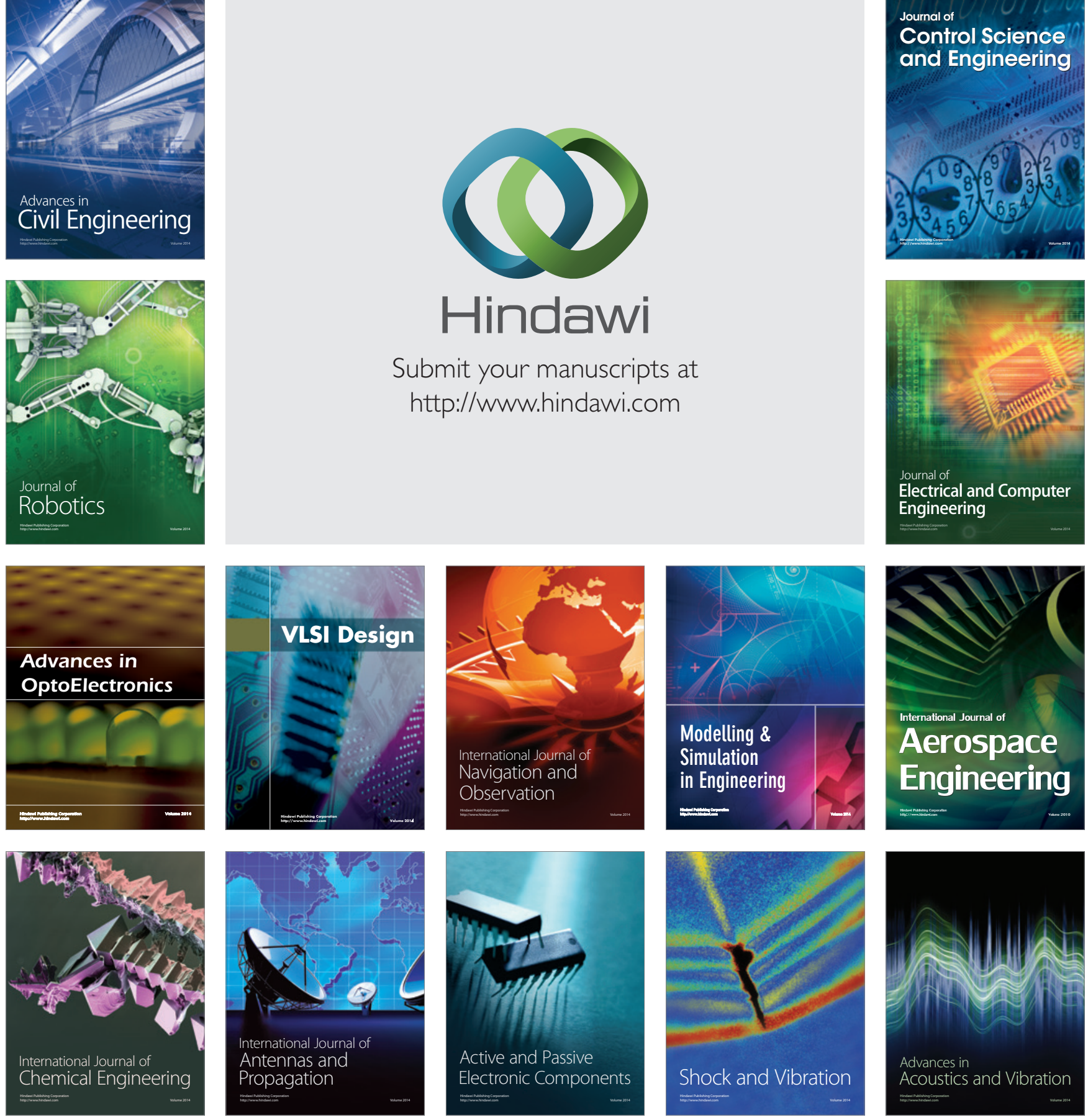